comunidad es significativo e importante desde el punto de vista disciplinar, ya que al hacerlo público brinda la oportunidad a toda la gente de un acceso educativo-cultural, pues ofrece nuevos conocimientos y vivencias de cierta población, y eso es precisamente lo que busca hoy en día el turismo alternativo: enriquecer la mente y el espíritu, buscando el turista obtener nuevas experiencias enriquecedoras para su vida.(Convención Europea para la Protección del Patrimonio Arqueológico, 1992)

Al interior del grupo de investigación para la Animación Cultural "MUISUATA" se viene impulsando varios proyectos en torno a estas temáticas como por ejemplo: el estado de arte de la investigación de Turismo Cultural, la valoración sobre las experiencias que ha venido adelantando el departamento de Boyacá, entre otros. En esta medida la pretensión es poder contribuir a la profundización del conocimiento en torno a este y poder así aportar al fortalecimiento de la línea de investigación del grupo "Turismo y Cultura".

\title{
BIBLIOGRAFIA
}

- Código Mundial de Ética del Turismo (CMET: 2001)

- Convección para la Protección del Patrimonio Mundial (UNESCO: 1972), la Carta sobre el Turismo Cultural (ICOMOS, 1976) y Cumbres como la de Rio (1992).

- Ministerio de Comercio, Industria y Turismo. Ministerio de Cultura, política de Turismo Cultural: identidad y Desarrollo competitivo del Patrimonio. (SECTUR 2001)

- RICHARDS, Greg. (1996). Políticas y Actuaciones en el Campo del Turismo Cultural Europeo. Universidad de Tilburg: Holanda.

- GOMEZ, R. Manuel. (2002) Patrimonio Cultural y Turismo.

\section{LA POLÍTICA MONETARIA COMO FUENTE DE CRECIMIENTO ECONÓMICO EN COLOMBIA}

\section{José Mauricio Gill León.}

Semillero: ANESPEC (Análisis Estructural de las Políticas Económicas en Colombia). Grupo: MODEAL (Modelos de Desarrollo de América Latina).

\section{Introducción}

En la política económica, la política monetaria tiene un papel preponderante sobre la actividad económica. Ésta tiene mecanismos de transmisión que, aunque han estado enfocados a la inflación objetivo y al mantenimiento de una política cambiaria que ayude a la competitividad del sector externo, han afectado al comportamiento del crecimiento económico.

En el documento se analiza la importancia de la política monetaria en la economía y su comportamiento después de la década de los noventa, donde finalmente se determinan sus efectos sobre la economía colombiana. 
se destacan dos periodos. El primero, se presentó en los noventa, donde se utilizó una banda cambiaria deslizante que en promedio fue de un $7 \%$ de ancho, que determinaba el precio de la divisa (dólar); esto ocasionó problemas en el manejo monetario, debido a que se presentó el trilema de la PM (tasa de interés, tasa de cambio y libre movilidad de capitales), el cual indica que no es posible influir en las tres variables simultáneamente (Gómez, 2006). El segundo, es a partir de 1999, donde se liberó el mercado cambiario, con una tasa de cambio flotante, que se determina con la entrada y salida de divisas con la intervención del BR, solo cuando esta pierde su competitividad para el intercambio comercial. Comportamiento de la política monetaria en los noventa

La inflación promedio en la primera mitad de los noventa estuvo en $25.5 \%$, después de estos años fue cayendo, hasta ubicarse en un digito en 1999. Hay que recalcar que hasta el 2001 la estrategia monetaria no pretendía disminuir la inflación, sino tan solo afectar la liquidez necesaria que requería sistema económico, y en este sentido la inflación era tomada como variable exógena. (Gómez, 2006). Desde 1991 hasta 1995, la PM fue expansiva, impulsada por la monetización no esterilizada de los capitales que entraron al país (en su mayoría deuda), que forzaba el aumento de los agregados monetarios, lo cual presionó al BR en 1996 a tomar medidas de control restrictivas en la tasa de interés. Después de 1997 por la crisis asiática y por la incertidumbre que generó, en Colombia se presentaron fuertes salidas de capitales que causaron una devaluación que presionaría la inflación, lo cual llevo a la autoridad monetaria a aplicar una política mas restrictiva por medio de la elevación de las tasas de interés, para atraer capitales y evitar la devaluación. Por intentar alcanzar el propósito anterior, se desacumularon reservas internacionales desculdando de ese modo, el estimulo a la economía interna, que luego en el 99 se reflejaría en una recesión que arrojo un crecimiento anual de $-4.2 \%$.

\section{Comportamiento de la política monetaria después del $\mathbf{2 0 0 0}$}

Después del 2000 cuando ya existía una inflación de un dígito, se presentó un relajamiento de la PM, donde la represión financiera fue cada vez menor $y_{r}$ por ende las tasas de interés fueron menores; la política pudo actuar de una manera mas independiente, por la liberación de las tasas de cambio, ya que únicamente se intervenía cuando existía problemas en la competitividad externa. Las tasas de interés del mercado bajaron, que en términos reales resultaron ser cercanas a cero. Además, el grado de transmisión es mayor, demostrado por la alta correlación entre las tasas de referencia y las de mercado, como es el caso de de la DTF, la tasa interbancaria y la de los TES, que se mueven en la misma dirección en menor tiempo.

La explicación de los descensos en la tasas de interés es por la menor inflación, 
que es un fenómeno que se ha controlado en casi todo el mundo, y en Colombia, se ha ubicado entre el 2000 y el 2008 en un promedio de $6.5 \%$.

Efectos en el crecimiento de la política monetaria

La PM, ha influido directamente en la economía nacional, teniendo en cuenta que la profundización financiera es cada vez mayor. La economía tuvo una relativa estabilidad en la primera mitad de la década de los noventa, con grandes entradas de capitales, que al monetizarlos se ampliaba el nivel de liquidez, lo cual era reflejado en la economía con menores tasas de interés, por tanto mayor inversión, ya que le stock de capital tuvo en esta primera mitad de los noventa un crecimiento de $6.6 \%$. El desempleo logró ser bajo en esta época, respaldado tal vez con políticas de expansión fiscal y monetaria. Cuando ocurrieron las turbulencias en la economía mundial, se hizo necesario contraer la liquidez para evitar el debilitamiento de la moneda, además, por la falta de financiación externa del gobierno, se hizo necesario vender TES en el mercado interno a una mayor tasa de interés restándole liquidez al sector privado, y reflejando las altas tasas en el mercado de crédito. En conclusión, la crisis del 99 estuvo antecedida de dicha contracción monetaria, que se reflejó en la disminución de la demanda agregada y caída de la inflación, que en los siguientes años estuvo controlada, por esta razón, se logró realizar una PM expansiva, que estimuló la demanda, el incremento del valor de los activos, y por tanto, generó crecimiento económico.

\section{FUENTES CONSULTADAS}

- CEMLA, (MELo VelANDIA, Luis Fernando, BECERRA CAMARgo, Oscar Reinaldo); Una descripción de la dinámica de la tasa de interés de corto plazo en Colombia. Vol XXXI numero 2, Abril-Junio 2008.

- CLAVIJO, Sergio, VARELA, Carlos; Flotación Cambiaria Y Esterilización Monetaria: La Experiencia de Colombia. Banco de la República, Julio de 2003.

- GAMARRA HERNÁNDEZ, Antonio, TOLOSA BUITRAGO, José; La Política Monetaria En Colombia En La Segunda Mitad De Los Años Noventa. Bogotá, 20 de Febrero del 2001.

- GÓMEZ, Javier Guillermo; La Política Monetaria en Colombia, Abril 21 de 2006.

- GRUPO MACROECONOMÍA (Gloria Alonso, Dayra Garrido, Alex Guarín, Franz Hamann, José Leibovich, Ignacio Lozano, Juan Mauricio Ramírez, Carolina Ramírez, Hernán Rincón, Juana Téllez, Jorge Toro); La Economía Colombiana: Situación Actual Frente A Los Noventa Y Sus Perspectivas, Banco de la República, Diciembre 2006.

- VILLAR GómEZ, Leonardo, SALAMANCA ROJAS, David M, MURCia PABÓN, Andrés; Crédito, Represión Financiera Y Flujos De Capitales En Colombia: 1974-2003, enero 2005. Banco de la República.

- ZULUAGA, Blanca; La Política Monetaria: Teoría Y Caso Colombiano. Apuntes De Economía, marzo de 2004, Departamento de Economía - Universidad ICESI.

- www.banrep.gov.co 